\title{
Aerztekammer für die Provinz Brandenburg und den Stadtkreis Berlin.
}

Die Aerztekammer für die Provinz Brandenburg und den Stadtkreis Berlin tagte am 19. November unter dem Vorsitz von Geh. Sanitätsrath Dr. Becher; als Regierungsvertreter war Oberpräsident v. Achenbach und Regierungsassessor Graf Pilaty erschienen. Beim ersten Punkt der Tagesordnung wurde eine Reihe geschäftlicher Dinge erledigt. Den verstorbenen Kammermitgliedern Hirsch und Flatow widmete der Vorsitzende einen ehrenden Nachruf. Von mehreren Wahlrechtsentziehungen seitens anderer Aerztekammern wurde Mittheilung gemacht. - An Stelle von Flatow und Schöneberg (wegen Krankheit ausgeschieden) wurden Guttstadt und Posner zu Vorstandsmitgliedern gewählt. - Ueber den dritten Punkt der Tagesordnung, den Antrag des Aerztevereins der Neumark betreffend die Selbsteinschätzung der Aerzte, referirte Joachim. Der Antrag des Aerztevereins, die Entscheidung des Oberverwaltungsgerichts vom 16 . November 1895 , wonach die Ausgaben der 
Aerzte für Fachlitteratnr, für Reisen zn medicinischen Versammlnngen, sowie fur schnellere Abnutznng der Kleider etc. nicht nnmittelbar znr Erwerbnng, Sichernng nnd Erhaltnng des ärztlichen Einkommens dienen und daher nicht als abzngsfähig erachtet werden können, als nnzıtreffend zn bezeichnen nnd die Angelegenheit der Honorarcommission mit der Weisung zn ïbergeben, zn geeigneter Zeit Vorschläge tür die $\mathrm{Ab}$ andernng des hentigen Rechtsznstandes zu machen. wird angenommen.

Ueber den vierten Pnnkt der Tagesordnnng (Referent Kossmann) entspann sich eine lebhafte Debatte. Am 12. Febrnar 1898 hatte der Polizeipräsident von Berlin eine Verfügnng erlassen, in welcher es nnter No. 1, Absatz 1 heisst: „Den in Anslande approbirten Personen, männlichen nnd weiblichen, die sich znr gewerbsmässigen Ansubnng der Heilknnde offentlich erbieten, ist die Führnng des Titels "Arzt", "praktischer Arzt", „praktische Aerztin“ im Geschäftsbetriebe nnr dann erlanbt, wenn der Titel mit einem seinen Ursprnng bezeichnenden Znsatz versehen ist, welcher für das Pnbliknm aller Stände den Irrthnm völlig ansschliesst, als sei die Approbation als Arzt in Dentschland erworben." Ferner nnter No. 1, Absatz 3: „In jedem Falle hat der Gewerbetreibende den Nachweis zn erbringen, dass Approbation oder Promotion gesetzlich erfolgt sind." Die Ansfürnngen Kossmann's gipfelten in der Ansicht, dass diese Verfugnngen nit den Interessen der öffentlichen Gesnndheitspflege und den bei Erlass der Reichsgewerbeordnnng maassgebend gewesenen Absichten der gesetzgebenden Factoren in Widersprnch stehen und geeignet seien, den Aerzten zu schaden, bezw. der Thätigkeit nicht approbirter Personen Vorschnb zu leisten. - Als Ergebniss der Berathnng, an der sich die Herron S Marcuse, Schäffer, Mngdan, Alexander, Kossmann, Mendel betheiligten, wnrde der Antrag Mendel angenommen, "den Herrn Oberpräsidenten zn ersnchen, von den Missständen, wie sie der Antrag Kossmann auffülrt. Kenntniss nehmen zu wollen, die ihm zweckmässig erscheinenden Schritte znr Abstellung dieser Missstäude ergreifen und der Aerztekammer davon Mittheilung machen zn wollen." - Nach seiner privation geänsserten Ansicht steht der Herr Oberpräsident anf dem Boden des Aerztekammerbeschlnsses und wird Veranlassnng nehmen, im Sinne desselben an znständigem Orte vorstellig zu werden.

Der fitinfte Pnnkt der Tagesordnnng (Anstellung einer Polizeiärztin in Berlin) wnrde anf Antrag des Referenten Joachim abgesetzt. - Znm sechsten Pnnkt „Die Medicinalreform" (Referent Alexander) wnrden die folgenden Sätze ingenommen:

I. Die Anfordernngen, welche die öffentliche Gesnndbeitspflege an die Thätigkeit der Gesnndheitsbeamten im Interesse des Allgemeinwohls zu stellen hat, erheischen nnbedingt eine Umgestaltnng der Medicinalbehörden.

II. Der Entwnrf eines Gesetzes, betreffend die Dienststellnng des Kreisarztes und die Bildnng von Gesnndheitscommissionen bietet zwar eine geeignete Grnndlage für die Reform einzelner Theile des preussischen Medicinalwesens, verburgt jedoch, da er wesentliche Missstände der jetzigen Organisation unberïicksichtigt lässt. nicht die Erreichnng derjenigeu Ziele, welche in der voul der Königlichen Staatsregierıng veröffentlichten Denkschrift ïber die Umgestaltung der Medicinalbehörden in Aussicht genommen sind.

1Il. Demgemäss bedürfen die Bestimmnngen des Entwurfes einer Aenderung, bezw. Erweiternng nach folgender Richtnng:

a) Der Kreisarzt ist vollbesoldeter, nnmittelbarer Staatsbeanter unit Wohnungsgeldzuschnss, Dienstanfwandsentschädigung nnd Pensionsberechtignng ( $\mathrm{zu} \& 3$ ).

b) Die Ansübnng ärztlicher Privatpraxis ist dem Kreisarzte nntersagt. Gestattet ist ihm die Theilnabme an gemeinschaftlicher Berathnng mit anderen Aerzten.

c) Der Kreisarzt hat die Aufgabe, an den Sitzungen des Kreisansschnsses ohne weiteres, an denen des Kreistages anf Ersnchen des Vorsitzenden mit berathender Stimme theilznnehmen (zu $\S 5$ ).

d) Der Kreisarzt hat die Anfgabe; auch ohne besonderen Auftrag seimen Anitsbezirk periodisch zu bereisen.

e) Dem Kreisarzte werden kreisärztlich geprifte Aerzte als Assistenten beigegeben, welche $\mathrm{ihm}$ dienstlich nnterstellt sind nnd eine angemessene Remnneration ans staatlichen Mitteln beziehen.

f) Die gerichtsärztliche Thätigkeit des Kreisarztes wird in der Regel nnd wenn nicht besondere lokale Verhältnisse die Vereinignng erfordern, ron den Dienstgeschäften des Kreisarztes getrennt (zn $\S 8$ ).

g) Dem Regiernngsmedicinalrath ist die Ansübnng jeglicher Privatpraxis nntersagt.

b) Für Zwecke des Gesundheitswesens müssen Untersnchungsanstalten unter staatlicher Anfsicht eingerichtet werden.

Der Rest der Tagesordnnng wurde anf dic nächste Kammersitznng. verschoben. 